\title{
Inflammation and endothelial activation in Benign Prostatic Hyperplasia and Prostate Cancer
}

\author{
Gianna Pace, Caterina Di Massimo, Daniela De Amicis, Carlo Vicentini, M. Giuliana Tozzi \\ Ciancarelli
}

Department of Health Sciences (GP, CM, DA, CV, MGTC), University of L'Aquila, Via Vetoio, 67100 L'Aquila and Urology Unit (GP, CV), Mazzini Hospital, Teramo, Italy

\begin{abstract}
Purpose: Emerging insights underline a link among chronic inflammation and endothelial activation with benign prostatic hyperplasia (BPH) and prostate cancer (PCa). We aim to investigate whether specific plasma markers of inflammation and endothelial activation allow to discriminate $\mathrm{BPH}$ and $\mathrm{PCa}$.

Materials and Methods: Fifteen patients affected by BPH, 15 by PCa and 15 controls, were enrolled. Interleukin-6 (IL-6), CD40 ligand (CD40L), endothelial-selectin (E-selectin), platelet-selectin (P-selectin), vascular cell adhesion molecule-1 (VCAM-1) and intercellular adhesion molecule-1 (ICAM-1) were measured.

Results: In systemic blood samples, IL-6 has been found increased in patients affected by BPH $(4.25 \pm 0 . \mathrm{pg} / \mathrm{mL})$ and $\mathrm{PCa}(5.08 \pm 0.24)$ respect to controls $(2.62 \pm 0.34 ; \mathrm{p}<0.05)$. CD40L was higher in BPH $(4.25 \pm 0.65 \mathrm{ng} / \mathrm{mL} ; \mathrm{p}$ $<0.05)$ than in control $(2.31 \pm 0.20)$ and PCa group $(2.60 \pm 0.56)$. E-selectin, P-selectin and VCAM-1 did not show any significant difference. Higher levels of ICAM-1 were detected in patients with PCa (573.04 \pm 52.23$)$ and BPH $(564.40 \pm 74.67)$ than in the controls $(215.30 \pm 11.53 \mathrm{ng} / \mathrm{mL} ; \mathrm{p}<0.05)$. In local blood samples, IL-6 has been found significantly increased in PCa in comparison with patients with BPH; there was no difference in CD40L, E-selectin, P-selectin, VCAM-1 ed ICAM-1.

Conclusions: Changes in inflammation and endothelial activation markers may be not considered to be of value in discriminating $\mathrm{BPH}$ and $\mathrm{PCa}$.
\end{abstract}

Key words: prostatic hyperplasia; prostatic neoplasms; biological markers; inflammation mediators; endothelial cells Int Braz J Urol. 2011; 37: 617-622

\section{INTRODUCTION}

The pathogenesis of $\mathrm{PCa}$ (prostate cancer) and BPH (benign prostatic hyperplasia) is still largely unresolved. The common key mechanisms involved in the development and progression of $\mathrm{PCa}$ and $\mathrm{BPH}$ are represented by ageing, hormonal alterations, metabolic syndrome and inflammation (1). Currently, a vast literature suggests a link between chronic inflammation and prostatic disease $(2,3)$. However, whether intraprostatic inflamma- tion may contribute to carcinogenesis and hypertrophy of prostate is still unknown. The molecular pathogenesis of prostate cancer has been characterized by somatic germline alterations of genes associated with some immunological aspects of inflammation in modulating prostate cancer risk. In support of this hypothesis, population studies pointed out an increased relative risk of prostate cancer in patients with a previous history of sexually transmitted infections or prostatitis (4-6). Proliferative inflammatory atrophy, which shares 
some molecular traits with prostate intraepithelial neoplasia and prostate cancer, has been recognized as a novel putative prostate cancer precursor lesion (7). Nonetheless, inflammation is frequently present in prostate biopsies, radical prostatectomy specimens and tissue resected for the treatment of benign prostatic hyperplasia. Moreover, proliferative inflammatory atrophy, often found inside and around foci of atrophy, may be considered as a precursor of an early prostate cancer or may indicate an intraprostatic environment favourable to cancer development.

In the last few years, the role of inflammation in the pathogenesis of BPH has been also advocated in supporting the process of fibromuscolar growth (3-7). The inflammatory injury may contribute to cytokine production by inflammatory cells driving local growth factor production and angiogenesis in the prostatic tissue. An up-regulation of pro-inflammatory cytokines has been reported in BPH tissue (8). This pro-inflammatory micro-environment is closely related to BPH stromal hyperproliferation and tissue remodelling with a local hypoxia induced by increased oxygen demands by proliferating cells which supports chronic inflammation as a source of oxidative stress leading to tissue injury in infiltrating area (9). When taken together, studies of sexually transmitted infections, clinical prostatitis, genetic and circulating markers of inflammation hint at a link between prostate cancer and chronic intraprostatic inflammation (10). Analyses on bacterial colonization in $\mathrm{PCa}$ and normal prostate tissue showed, indeed, a highly suggestive correlation between bacterial colonization/chronic inflammation and $\mathrm{PCa}$ as well as BPH. The hypothesis that inflammation might promote $\mathrm{PCa}$ and $\mathrm{BPH}$ is actually supported by several new significant findings. On the basis of these suggestions, aim of this study has been to investigate the possible significance of markers related to inflammation and endothelial activation as discriminative indexes of $\mathrm{PCa}$ or $\mathrm{BPH}$. For this purpose, we measured, in blood samples withdrawn both locally in the prostate gland and systemically, interleukin-6 (IL-6), CD40 ligand (CD40L), endothelial-selectin (E-selectin), platelet-selectin (P-selectin), vascular cell adhesion molecule-1 (VCAM-1) and intercellular adhesion molecule-1 (ICAM-1) as specific markers of inflammation and endothelial activation.

\section{MATERIALS AND METHODS}

A total of 45 consecutive patients, hospitalized in our Urological Department between February and July 2008, 15 affected by BPH, 15 by PCa and 15 controls were selected for the current study. The research has been carried out in accordance with the Declaration of Helsinki and approved by the Ethics Committee of our hospital. Consent was obtained from all patients after full explanation of the procedure. Details about the criteria of selection and methodological procedures have been just described in a previous study (11).

In serum and plasma blood samples we measured: IL-6, CD40L, E-selectin, P-selectin, VCAM-1 and ICAM-1. Plasma and serum samples were stored at $-80^{\circ} \mathrm{C}$ until analysis.

VCAM-1 and ICAM-1 levels (ng/mL) were measured using ELISA kits (Bender MedSystems $\mathrm{GmbH}$, Campus Vienna Biocenter, Austria), with a sensitivity of $0.59 \mathrm{ng} / \mathrm{mL}$ and $2.17 \mathrm{ng} / \mathrm{mL}$, an intraassay CV of $3.1 \%$ and $4.1 \%$, an inter-assay CV of $5.2 \%$ and $7.6 \%$, respectively.

P-selectin and E-selectin levels $(\mathrm{ng} / \mathrm{mL})$ were measured using ELISA kits (Bender MedSystems $\mathrm{GmbH}$, Campus Vienna Biocenter, Austria), with a sensitivity of $1.06 \mathrm{ng} / \mathrm{mL}$ and $0.30 \mathrm{ng} / \mathrm{mL}$, an intra-assay CV of $2.4 \%$ and $5.4 \%$, an inter-assay $\mathrm{CV}$ of $5.2 \%$ and $6.0 \%$, respectively.

CD40L level $(\mathrm{ng} / \mathrm{mL})$ was measured using a high sensitivity ELISA kit (Bender MedSystems $\mathrm{GmbH}$, Campus Vienna Biocenter, Austria) with a sensitivity of $0.005 \mathrm{ng} / \mathrm{mL}$, an intra-assay $\mathrm{CV}$ of $5.5 \%$ and an inter-assay CV of $6.6 \%$. IL-6 level $(\mathrm{pg} / \mathrm{mL})$ was measured using an ELISA kit (Bender MedSystems GmbH, Campus Vienna Biocenter, Austria), with a sensitivity of $0.92 \mathrm{pg} / \mathrm{mL}$, an intraassay CV of 3.4\%, an inter-assay CV of 5.2\%.

SPSS for Windows (version 10.0.7) computer package was used for statistical analysis. All data are given as mean \pm standard error of the mean (SEM). Mann-Whitney rank sum test was used to compare differences between all patients enrolled and the control group. Wilcoxon matched-pairs signed rank test was used to compare differences between local and systemic samples. Statistical significance was accepted if $\mathrm{p}<0.05$. 


\section{RESULTS}

As reported in Table-1, in systemic blood samples we found an increased level of IL-6 in patients affected by BPH $(4.25 \pm 0.36 \mathrm{pg} / \mathrm{mL})$ and $\mathrm{PCa}(5.08 \pm 0.24)$ in respect to controls $(2.62 \pm$ $0.34 ; \mathrm{p}<0.05)$. This raise was significantly greater in patients with $\mathrm{PCa}$ than in those affected by BPH. CD40L was increased in BPH group (4.25 $\pm 0.65 \mathrm{ng} / \mathrm{mL} ; \mathrm{p}<0.05)$ respect to controls $(2.31$ \pm 0.20 ). Notably, in PCa patients we observed an increased value of CD40L statistically significant versus control group but not in comparison with
$\mathrm{BPH}$ patients. No significant differences were observed in E-selectin, P-selectin and VCAM-1 among the three groups. Higher levels of ICAM-1 were detected in patients with both PCa (573.04 $\pm 52.23)$ and BPH $(564.40 \pm 74.67)$ than in the control group $(215.30 \pm 11.53 \mathrm{ng} / \mathrm{mL} ; \mathrm{p}<0.05)$. However, no statistical significant difference was found in ICAM-1 between PCa and BPH. In local blood samples, IL-6 has been found significantly increased in $\mathrm{PCa}(7.14 \pm 0.47)$ in comparison with $\mathrm{BPH}$ patients $(6.35 \pm 0.94)$. No significant differences were detected in CD40L, E-selectin, P-selectin, VCAM-1 ed ICAM-1 (Table-2).

Table 1 - Parameters measured in systemic blood samples.

\begin{tabular}{llll}
\hline & Control & PCa & BPH \\
\hline IL-6 $(\mathrm{pg} / \mathrm{mL})$ & $2.62 \pm 0.34$ & $5.08 \pm 0.24^{*}$ & $4.25 \pm 0.36^{* * *}$ \\
CD40L $(\mathrm{ng} / \mathrm{mL})$ & $2.31 \pm 0.20$ & $2.60 \pm 0.56$ & $4.25 \pm 0.65^{* * *}$ \\
E selectin $(\mathrm{ng} / \mathrm{mL})$ & $54.67 \pm 1.01$ & $38.65 \pm 5.23^{*}$ & $39.88 \pm 8.20^{*}$ \\
P selectin $(\mathrm{ng} / \mathrm{mL})$ & $125.58 \pm 0.84$ & $45.71 \pm 6.45^{*}$ & $37.94 \pm 4.31^{*}$ \\
VCAM-1 $(\mathrm{ng} / \mathrm{mL})$ & $809.96 \pm 26.48$ & $333.65 \pm 33.54^{*}$ & $361.97 \pm 32.68^{*}$ \\
ICAM-1 $(\mathrm{ng} / \mathrm{mL})$ & $215.30 \pm 11.53$ & $573.04 \pm 52.23^{*}$ & $564.40 \pm 74.67 *$ \\
\hline
\end{tabular}

$* P<0.05$ vs Control values; ** $P<0.05$ vs PCa values; $P C a$ : prostate cancer; BPH: benign prostatic hyperplasia.

Table 2 - Parameters measured in local blood samples.

\begin{tabular}{lll}
\hline & PCa & BPH \\
\hline IL-6 $(\mathrm{pg} / \mathrm{mL})$ & $7.14 \pm 0.47$ & $6.35 \pm 0.94^{*}$ \\
CD40L $(\mathrm{ng} / \mathrm{mL})$ & $1.99 \pm 0.54$ & $3.16 \pm 0.76$ \\
E selectin $(\mathrm{ng} / \mathrm{mL})$ & $34.32 \pm 5.43$ & $29.62 \pm 4.25$ \\
P selectin $(\mathrm{ng} / \mathrm{mL})$ & $177.80 \pm 39.74$ & $73.52 \pm 12.63$ \\
VCAM-1 $(\mathrm{ng} / \mathrm{mL})$ & $411.15 \pm 68.80$ & $383.53 \pm 98.29$ \\
ICAM-1(ng/mL) & $496.17 \pm 36.49$ & $466.04 \pm 52.73$ \\
\hline
\end{tabular}

$* P<0.05$ vs PCa values; PCa: prostate cancer; BPH: benign prostatic hyperplasia 


\section{DISCUSSION}

The identification of biomarkers, assessable in blood samples, in patients affected by PCa and BPH could be useful in order to differentiate those common prostate diseases as well as to identify specific therapeutic strategies. Patterns of inflammation and endothelial activation seem to offer a biological link between pathogenesis and clinical symptoms of prostatic disease as well as might predict the onset and progression of both $\mathrm{PCa}$ and $\mathrm{BPH}$. Several studies support a close relation between BPH and the inflammatory pattern, as suggested by the increased rate $(61 \%)$ of signs of chronic inflammation in prostates of greater volume $(80-89 \mathrm{~mL})$ respect to small ones (12). As prostate size is a valuable predictor of $\mathrm{BPH}$ progression, the relationship between prostate size and chronic inflammation should be indicative of worsening clinical development. Clinical evidence reports that chronic inflammation represents a key condition leading to prostate enlargement and to an increased symptoms score as well as a major risk of complications (3). Furthermore, when inflammation is clinically supposed and then proven histologically, it may be taken into account in the management and treatment of BPH. IL-6 is a pleiotropic cytokine and one of the main mediators of the acute phase reaction, produced by fibroblasts, activated macrophages or monocytes, activated $\mathrm{T}$ and $\mathrm{B}$ cells, endothelial cells, stromal cells (9). Besides, dysregulation of the immune response in BPH may occur via elevated expression of pro-inflammatory IL-17 which stimulates, in turn, IL-6 and-8 production responsible for stromal growth factor (3). According to these suggestions, we found IL-6 to be increased systemically in $\mathrm{BPH}$ respect to control group. This result confirms the involvement of IL- 6 in the onset of BPH and could suggest its possible significance in discriminating prostate inflammatory hypertrophy in comparison normal gland tissue. A central role of the endothelial activation is also supported in the onset and progression of BPH by systemically increased levels of both CD40L and ICAM-1. It is well known that $\mathrm{CD} 40 / \mathrm{CD} 40 \mathrm{~L}$ is involved in angiogenesis. Notably, CD40, demonstrated to be higher in advanced lung cancer, is also secreted by neoplastic prostatic epithelial cells by acting as a growth factor (13). In prostatic tumoral glandular tissue, CD40 is secreted with a higher rate in hormone-refractory phase, with a relevant importance in PCa progression (14). Tumorogenesis and progression are characterized by changed expression of cell adhesion molecules that are over-expressed in progressive disease and metastasis. However, current evidence underlines that expression of cell adhesion molecules may be not useful, over PSA, in differentiating $\mathrm{PCa}$ from $\mathrm{BPH}$ as well as for PCa diagnosis and follow-up (15). Moreover, E-selectin has been demonstrated to be constitutively expressed on bone marrow endothelial cells which represents the preferentially adhesive mechanism promoting haematogenous dissemination of prostate tumor cells into bone. Therefore, the acquisition of E-selectin ligand expression may be associated with prostate tumor progression (16). As showed by Shariat et al., increased plasma levels of IL-6, soluble IL-6 receptor, vascular endothelial growth factor, VCAM-1, endoglin, urokinase-type plasminogen activator and its receptor, plasminogen activator inhibitor-1, may be of value in predicting the risk of disease relapse after RP in respect to standard clinical variables, by $15 \%$ to $86.6 \%$ (17). E-selectin, expressed as a consequence of a hypoxic vascular condition, is up-regulated in $\mathrm{PCa}$ as result of complex interactions of tumor microenvironment and it is associated with tumor angiogenesis and metastasis (18). It has been reported that serum levels of E-selectin, ICAM-1, VCAM-1 analyzed in colorectal cancer were significant prognostic factors for patients survival, even though independent on tumor progression and metastasis (19). In metastatic prostate cancer, ICAM-1 and VCAM-1 seem to correlate with the metastatic stage while no differences were found between patients with localized cancer and controls (15). Our results are in accord with this assumption as we did not find, locally, a significant increase in ICAM-1, VCAM-1, P-selectin and E-selectin in patients affected by PCa (20). In our opinion, we suggest that it should be due to the restrict selection criteria, namely patients with a localized prostate cancer T2. Further, in relation with the pro-inflammatory pathway, we found IL- 6 to be higher locally in $\mathrm{PCa}$ than in BPH patients $(<0.05)$ and systemically respect to controls.

On one hand, our study confirms that in localized prostate cancer, cellular adhesion molecules are not increased and they do not appear to be useful 
in differencing localized PCa from BPH. On the other hand, we suggest that any selected serum markers may be of utility in evaluating tumor activity, for identifying metastatic potential or predicting progression. The identification of easily assessable circulating biomarkers, in patients who are likely to fail radical prostatectomy, might be of value to counsel them about the risk of biochemical recurrence. Toward this end, further studies on advanced prostate cancer are needed in evaluating more useful markers to predict metastasis and progression.

\section{CONCLUSIONS}

In $\mathrm{BPH}$, inflammation may be taken into account in the correct selection of treatment choice as whether detected those patients should have a symptomatic beneficial improvement by adding anti-inflammatory drugs to standard therapies.

Changes of the inflammation and of the endothelial activation specific markers observed in patients affected by BPH and PCa may be not considered of value in discriminating those prostate diseases.

\section{CONFLICT OF INTEREST}

None declared.

\section{ABBREVIATIONS}

Benign prostatic hyperplasia: $\mathrm{BPH}$

Prostate cancer: $\mathrm{PCa}$

Interleukin-6: IL-6

CD40 ligand: CD40L

Endothelial-selectin: E-selectin

Platelet-selectin: P-selectin

Vascular cell adhesion molecule-1: VCAM-1

Intercellular adhesion molecule-1: ICAM-1

Standard error of the mean: SEM

\section{REFERENCES}

1. Thompson TC, Yang G: Regulation of apoptosis in prostatic disease. Prostate Suppl. 2000; 9: 25-8.
2. Untergasser G, Madersbacher S, Berger P: Benign prostatic hyperplasia: age-related tissue-remodeling. Exp Gerontol. 2005; 40: 121-8.

3. Kramer G, Mitteregger D, Marberger M: Is benign prostatic hyperplasia (BPH) an immune inflammatory disease? Eur Urol. 2007; 51: 1202-16.

4. Bierhoff E, Vogel J, Benz M, Giefer T, Wernert N, Pfeifer U: Stromal nodules in benign prostatic hyperplasia. Eur Urol. 1996; 29: 345-54.

5. Bostwick DG, de la Roza G, Dundore P, Corica FA, Iczkowski KA: Intraepithelial and stromal lymphocytes in the normal human prostate. Prostate. 2003; 55: 187-93.

6. Steiner GE, Djavan B, Kramer G, Handisurya A, Newman M, Lee C, et al.: The picture of the prostatic lymphokine network is becoming increasingly complex. Rev Urol. 2002; 4: 171-7.

7. Palapattu GS, Sutcliffe S, Bastian PJ, Platz EA, De Marzo AM, Isaacs WB, et al.: Prostate carcinogenesis and inflammation: emerging insights. Carcinogenesis. 2005; 26: $1170-81$.

8. Handisurya A, Steiner GE, Stix U, Ecker RC, Pfaffeneder-Mantai S, Langer D, et al.: Differential expression of interleukin-15, a pro-inflammatory cytokine and T-cell growth factor, and its receptor in human prostate. Prostate. 2001; 49: 251-62.

9. Giri D, Ittmann M: Interleukin-8 is a paracrine inducer of fibroblast growth factor 2, a stromal and epithelial growth factor in benign prostatic hyperplasia. Am J Pathol. 2001; 159: 139-47.

10. Vasto S, Carruba G, Candore G, Italiano E, Di Bona D, Caruso C: Inflammation and prostate cancer. Future Oncol. 2008; 4: 637-45.

11. Pace G, Di Massimo C, De Amicis D, Corbacelli C, Di Renzo L, Vicentini C, et al.: Oxidative stress in benign prostatic hyperplasia and prostate cancer. Urol Int. 2010; 85: 328-33.

12. Di Silverio F, Gentile V, De Matteis A, Mariotti G, Giuseppe V, Luigi PA, et al.: Distribution of inflammation, pre-malignant lesions, incidental carcinoma in histologically confirmed benign prostatic hyperplasia: a retrospective analysis. Eur Urol. 2003; 43: 164-75.

13. Roselli M, Mineo TC, Basili S, Martini F, Mariotti S, Aloe S, et al.: Soluble CD40 ligand plasma levels in lung cancer. Clin Cancer Res. 2004; 10: 610-4.

14. Cabrespine A, Bay JO, Verrelle P, Morel L: Interleukin-6 implication in prostate cancer. Bull Cancer. 2007; 94(7 Suppl): F29-34.

15. Perabo F, Sharma S, Gierer R, Wirger A, Fimmers R, Steiner G, et al.: Circulating intercellular adhesion molecule-1 (ICAM-1), vascular cell adhesion molecule-1 (VCAM-1) and E-selectin in urological malignancies. Indian J Cancer. 2001; 38: 1-7. 
16. Dimitroff CJ, Lechpammer M, Long-Woodward D, Kutok JL: Rolling of human bone-metastatic prostate tumor cells on human bone marrow endothelium under shear flow is mediated by E-selectin. Cancer Res. 2004; 64: 5261-9.

17. Shariat SF, Karam JA, Walz J, Roehrborn CG, Montorsi F, Margulis V, et al.: Improved prediction of disease relapse after radical prostatectomy through a panel of preoperative blood-based biomarkers. Clin Cancer Res. 2008; 14: 3785-91.

18. Bhaskar V, Law DA, Ibsen E, Breinberg D, Cass KM, DuBridge RB, et al:: E-selectin up-regulation allows for targeted drug delivery in prostate cancer. Cancer Res. 2003; 63: 6387-94.

19. Alexiou D, Karayiannakis AJ, Syrigos KN, Zbar A, Kremmyda A, Bramis I, et al.: Serum levels of E-selectin, ICAM-1 and VCAM-1 in colorectal cancer patients: correlations with clinicopathological features, patient survival and tumour surgery. Eur J Cancer. 2001; 37: 2392-7.

20. Heidenreich A, Aus G, Bolla M, Joniau S, Matveev VB, Schmid HP, et al.: EAU guidelines on prostate cancer. Eur Urol. 2008; 53: 68-80.

\section{Correspondence address:}

\section{Dr. Gianna Pace}

Department of Health Sciences, University of L'Aquila,

San Salvatore Street, Palace 6 A, Coppito, 67100, L'Aquila, Italy.

Fax: + 3908 6121-1626

E-mail: giannapace@gmail.com 